\title{
Autocrine and/or paracrine growth of aggressive ATLL cells caused by HGF and c-Met
}

\author{
Y. ONIMARU ${ }^{1}$, K. TSUKASAKI ${ }^{1}$, K. MURATA ${ }^{5}$, Y. IMAIZUMI ${ }^{1}$, Y.L. CHOI ${ }^{6}$, H. HASEGAWA ${ }^{3}$, \\ K. SUGAHARA ${ }^{3}$, Y. YAMADA ${ }^{3}$, T. HAYASHI ${ }^{7}$, M. NAKASHIMA ${ }^{2}$, T. TAGUCHI $^{4}$, \\ H. MANO ${ }^{6}$, S. KAMIHIRA ${ }^{3}$ and M. TOMONAGA ${ }^{1}$
}

\begin{abstract}
${ }^{1}$ Department of Hematology and Molecular Medicine, ${ }^{2}$ Division of Scientific Data Registry, Atomic Bomb Disease Institute, Departments of ${ }^{3}$ Laboratory Medicine, and ${ }^{4}$ Pathology, Nagasaki University Graduate School of Biomedical Sciences, Nagasaki; ${ }^{5}$ Division of Hematology/Clinical Laboratory Medicine, Tottori University, Yonago, Tottori;

${ }^{6}$ Division of Functional Genomics, Jichi Medical University, Shimotsukeshi, Tochigi;

${ }^{7}$ Department of Pathology, Nagasaki University Hospital, Nagasaki, Japan
\end{abstract}

Received April 14, 2008; Accepted June 20, 2008

DOI: 10.3892/ijo_00000055

\begin{abstract}
Adult T-cell leukemia/lymphoma (ATLL) is a neoplasia characterized by the massive invasion of various organs by tumor cells. Previously, we found that expression of the gene for c-Met, a receptor tyrosine kinase for hepatocyte growth factor (HGF), was specific to the acute type among 41 patients with ATLL by microarray. First in the present study, we analyzed the survival of the patients in relation to expression of c-Met and HGF in ATLL cells. Expression of the former but not the latter was associated with poor prognosis. Then, we analyzed the growth of ATLL cells caused by HGF and c-Met. c-Met was expressed in 0/7 chronic ATLLs, 12/14 acute ATLLs, 1/1 IL-2-independent ATLL cell line and 1/7 IL-2-dependent ATLL cell lines as assessed by flow cytometry. HGF induced the proliferation of primary cells from most acute cases examined as well as the c-Met-positive KK1 cell line in contrast to c-Metnegative cells. HGF induced autophosphorylation of c-Met in c-Met-positive cells from an acute case and KK1 cells. The plasma level of HGF was elevated in acute as compared to chronic cases. The levels of HGF and/or IL-6 which induces the production of HGF by stromal cells, were elevated in the supernatant of short-term cultured cells from certain patients with acute or chronic disease. Finally, infiltrated ATLL cells
\end{abstract}

Correspondence to: Dr Kunihiro Tsukasaki, Department of Molecular Medicine and Hematology, Molecular Medicine Unit, Atomic Bomb Disease Institute, Nagasaki University Graduate School of Biomedical Science, 1-12-4 Sakamoto, Nagasaki 852-8523, Japan

E-mail: tsukasak@net.nagasaki-u.as.jp

Key words: adult T-cell leukemia/lymphoma, human T-lymphotropic virus type-I, c-Met, hepatocyte growth factor, autocrine/ paracrine and adjacent stromal cells in liver were shown to be positive for c-Met/HGF and HGF, respectively, in acute cases. Autocrine and/or paracrine growth caused by HGF and c-Met was suggested in aggressive ATLL cells secreting HGF and/or IL-6, respectively.

\section{Introduction}

Adult T-cell leukemia/lymphoma (ATLL) is a distinct peripheral T-lymphocytic malignancy associated with human Tcell lymphotropic virus type-I (HTLV-1) (1-3). The diverse clinical features and prognosis of this disease have led to its subclassification; acute, lymphoma, chronic, and smoldering types (4). Patients with indolent ATLL, i.e. the chronic or smoldering type, have been treated as a subtype of chronic lymphoid leukemia with a watchful-waiting policy until disease progression (5-7). Aggressive ATLL generally has a very poor prognosis as compared to aggressive B-cell lymphoma and peripheral T-cell lymphoma excluding ATLL because of the multidrug-resistance of malignant cells, a large tumor burden with multi-organ failure, hypercalcemia and/or frequent infectious complications due to a profound T-cell immunodeficiency (5-7).

Hepatocyte growth factor (HGF), also known as scatter factor, was identified as a chemoattractant for a variety of cells. HGF is produced by cells of mesenchymal origin, but not by epithelial cells and has a pleiotropic function, such as liver regeneration. It also has mitogenic, morphogenic, and motogenic effects on epithelial cells, as well as endothelial cells (8). The receptor for HGF is encoded by the met protooncogene (c-Met). The c-Met protein is a tyrosine kinase cell surface receptor and consists of an extracellular $\alpha$ - and a transmembrane $\beta$ chain. The $\beta$ chain contains the tyrosine kinase domain as well as the site for tyrosine autophosphorylation. Ligation of HGF causes autophosphorylation of c-Met, followed by a variety of signaling cascades (9). Although normal HGF/c-Met signaling is involved in many aspects of embryogenesis, abnormal HGF/c-Met signaling has been implicated in tumor development and progression 
$(10,11)$. In particular, HGF/c-Met signaling has been shown to play a significant role in promoting tumor cell invasion and metastasis. Furthermore, HGF and/or c-Met expression/overexpression has been documented in a wide variety of human tumors $(10,11)$. c-Met is predominantly expressed in epithelial cells but has been detected in various hematopoietic cells as well (12). Furthermore, lymphoid malignancies, such as multiple myeloma and several B cell lymphomas, were found to express c-Met, suggesting that c-Met is involved in the pathogenesis of these diseases $(13,14)$.

We have reported frequent hepatic involvement and the relationship between liver invasion and poor prognosis in ATLL, and the relationship was associated with c-Met expression on ATLL cells $(15,16)$. Recently, using microarray-based gene expression profiling, we performed a comprehensive genomic analysis of ATLL in order to investigate the mechanism of progression from chronic to acute disease, and found that c-Met expression was shown to be specific to acute type ATLL and the plasma concentration of HGF was increased in some individuals with acute or chronic type ATLL (17).

To clarify the interaction of c-Met/HGF in the multistep leukemogenesis and tissue-invasiveness of ATLL, we investigated the possible autocrine/paracrine loop using ATLL cell lines, and primary leukemic cells and liver autopsy specimens from patients with the disease.

\section{Materials and methods}

Clinical and microarray data for analyzing the relationship of prognosis and c-Met/HGF expression in ATLL. Isolated $\mathrm{CD}^{+}{ }^{+}$leukemic cells from cases of the chronic $(\mathrm{n}=19)$ or acute $(n=22)$ ATLL had been subjected to profiling of gene expression with oligonucleotide microarrays containing $>44,000$ probe sets including those for c-Met and HGF in our previous study (17). Collected clinical data for each patient were correlated with the expression data in this study.

Cell lines. Eight HTLV-I-positive T-cell lines were used. Six of the 7 cell lines established by us, SO4, ST1, KK1, KOB, LMY-1 and LMY2 excluding OMT, were each derived from a primary ATLL clone confirmed by Southern blotting for HTLV-1-integrated sites. The origin of HUT102 is unknown. HUT102, an interleukin (IL)-2-independent cell line, was grown in RPMI-1640 medium supplemented with $10 \%$ heatinactivated FBS, penicillin G (50 units/ml), and streptomycin $(50 \mu \mathrm{g} / \mathrm{ml})$ in a humidified incubator containing $5 \% \mathrm{CO}_{2}$ in air. The other 7 cell lines were IL-2-dependent, and were grown in a medium identical to that for HUT102 with 200 Japan reference units (JRUs)/ml recombinant IL-2 (provided by Takeda Chemical Industries, Osaka, Japan).

Patient samples for analyzing the growth of ATLL cells caused by HGF and c-Met. We assessed 21 patients with ATLL, 14 and 7 with acute and chronic types, respectively, having $>90 \%$ ATLL cells phenotypically confirmed by more than two parameters among CD2, CD3, CD4, CD5 and CD25 in peripheral blood mononuclear cells (PBMNCs). Four out of the 21 patients ( 3 acute types and 1 chronic type) were included in our previous study (17). The diagnosis of ATLL was based on clinical features, hematological findings including cytologically or histologically proven mature T-cell leukemia/lymphoma, and serum antiHTLV-I antibodies $(16,17)$. Integration of the monoclonal HTLV-I provirus into the genomic DNA of malignant cells was confirmed by Southern blot hybridization in all cases. PBMNC and plasma from patients with ATLL were obtained by density gradient separation from peripheral blood, before chemotherapy, with informed consent. PBMNCs and plasma were also obtained from healthy individuals.

Detection of c-Met protein on the cell surface by flow cytometric analysis. The expression of c-Met on the cell surface was analyzed by flow cytometry as described (17). Briefly, $3-5 \times 10^{5}$ cells were washed twice with PBS containing $2 \%$ FBS (FBS/PBS). The cells were incubated at $4^{\circ} \mathrm{C}$ with a mouse anti-human c-Met MoAb (Do-24; Upstate Biotechnology, Lake Placid, NY) for $60 \mathrm{~min}$. After being washed twice with FBS/PBS, they were incubated with FITC-labeled anti-mouse IgG MoAb (PharMingen), washed twice with FBS/PBS, and suspended in FBS/PBS. Thereafter, the cells were incubated with murine mAbs to human CD4 and CD25, respectively conjugated with phycoerythrin (PE) and perCP. They were analyzed by FACScan using CellQuest software (Becton-Dickinson), and positivity for c-Met was evaluated in CD4 and CD25 double positive ATLL cells.

Detection of autophosphorylation of c-Met protein. Cell lines and primary ATLL cells were incubated in the presence or absence of human recombinant HGF (Sigma). To analyze the autophosphorylation of c-Met in response to HGF treatment, cellular lysates were immunoprecipitated with c-Met-specific antibody on $10 \%$ SDS-PAGE gels, electrophoretically transferred to polyvinylidine difluoride membranes (ImmobilonP; Millipore Corp., Bedford, MA), and then analyzed for immunoreactivity with a mouse anti-human c-Met polyclonal antibody (Santa Cruz Biotechnology, Santa Cruz, CA) or antiphosphotyrosine antibody (anti-PY, 4G10), and horseradish peroxidase-conjugated sheep anti-mouse $\mathrm{IgG}$ (Amersham Life Science, Inc., Arlington Heights, IL) with an enhanced chemiluminescence detection system (Amersham Life Science, Inc.).

Proliferation assay. For assays of cell proliferation, IL-2deprived KK-1 cells and primary ATLL cells were cultured at a density of $5 \times 10^{5} / \mathrm{ml}$ and $1 \times 10^{6} / \mathrm{ml}$ viable cells assessed by trypan blue staining, respectively, in 96-well flat-bottomed microtitre plates in $200 \mu \mathrm{l}$ of RPMI-1640 medium containing $10 \%$ FBS, 2 mmol/1 L-glutamine and antibiotics, with or without human recombinant HGF (Sigma), anti-human HGF $\mathrm{Ab}(\mathrm{R} \& \mathrm{D})$ or anti-human HGF R(c-Met) Ab (R\&D) for $48 \mathrm{~h}$, and were then mixed with MTS [3-(4,5-dimethylthiazol2-yl)-5-(3-carboxymethoxyphenyl)-2-(4-sulfophenyl)-2Htetrazolium, inner salt]. Cell proliferation was measured with a CellTiter 96 Aqueous One Solution Cell Proliferation Assay (Promega, Madison, WI, USA). All samples were analyzed in triplicate.

Cytokine assay. MNCs from patients with ATLL, normal individuals, or cell lines were suspended in RPMI-1640 

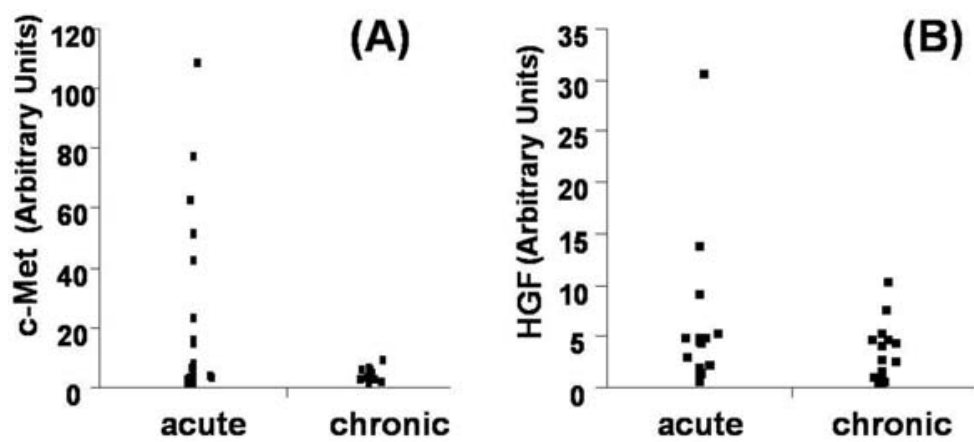

(C)
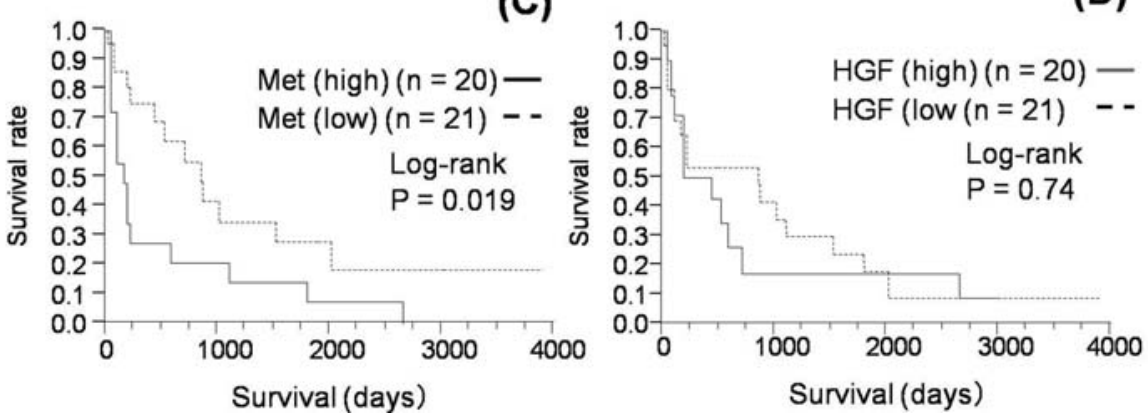

Figure 1. Expression level of c-Met but not HGF was associated with clinical subtypes of ATLL and prognosis. (A) Expression levels of c-Met and HGF by microarrays were compared between 22 acute cases and 19 chronic cases of ATLL. Leukemic CD4 positive cells from acute ATLL expressed significantly more c-Met than those from chronic ATLL (25.0 unit vs. 16.4 unit, $\mathrm{p}=0.021$ by Mann-Whitney test). (B) In contrast, the difference was not significant for HGF (23.5 unit vs. 18.1, p=0.15 by Mann-Whitney test). (C) Overall survival of 41 ATLL patients in relation to c-Met expression status analyzed by microarray. (D) Overall survival of 41 ATLL patients in relation to HGF expression status analyzed by microarray.

medium containing $10 \%$ fetal bovine serum (M.A. Bioproducts, Walkersville, MD) and $200 \mathrm{JRM} / \mathrm{ml} \mathrm{IL-2}$ at a concentration of $5 \times 10^{5} / \mathrm{ml}$ and $2 \times 10^{6} / \mathrm{ml}$ viable cells assessed by trypan blue staining, respectively. After $72 \mathrm{~h}$ of incubation, supernatant fluid was collected for assays. We examined the concentrations of HGF and IL- 6 in the plasma and the supernatant fluid samples by enzyme-linked immunosorbent assay (Quantikine; R\&D).

Immunohistochemistry. Using a formalin-fixed, paraffinembedded section of liver from autopsy specimens, we performed immunohistochemical analysis. The antibodies used were a rabbit polyclonal antibody against c-Met (SC-10, Santa Cruz Biotechnology) at 1:20 dilution and a rabbit polyclonal antibody against HGF (SC-7949, Santa Cruz Biotechnology) at 1:20 dilution (18). Tissue blocks were sectioned at 5-micron thickness and were put on coated slide glass. After deparaffinization, the sections were pretreated in $\mathrm{pH} 6.0$ citrate buffer by microwave for $10 \mathrm{~min}$ for antigen retrieval. The tissues were incubated with $3 \% \mathrm{H}_{2} \mathrm{O}_{2}$ to block unspecific reaction for $5 \mathrm{~min}$. After washing with PBS, the tissue were incubated with the first antibody for $1 \mathrm{~h}$ in room temperature, then, washed with PBS, and were incubated with DAKO EnVision system for $30 \mathrm{~min}$. The stains were visualized with DAB.

\section{Results}

Expression level of c-Met but not HGF was associated with clinical subtypes of ATLL and prognosis (Fig. 1). Expression levels of c-Met and HGF by oligonucleotide microarrays were compared between 22 acute cases and 19 chronic cases of ATLL. Leukemic CD4 positive cells from acute ATLL expressed significantly more c-Met than those from chronic ATLL. In contrast, the difference was not significant for HGF. Also, high expression of c-Met but not HGF was associated with worse overall survival.

Expression of c-Met protein in leukemic cells from ATLL patients. To examine the expression of c-Met on primary ATLL cells, FCM-based analyses were performed using PBMCs freshly isolated from ATLL patients as described previously (17). We observed the expression of c-Met on CD4 and CD25 double positive ATLL cells from 12 of 14 patients with acute-type ATLL, but none of 7 patients with chronic-type ATLL (Table I). c-Met was expressed in HUT 102 and KK1, which were IL-2 independent and dependent cell lines, respectively.

Autophosphorylation of c-Met was induced in HTLV-Ipositive T-cell lines and primary ATLL cells by HGF treatment. To examine whether the c-Met expressed in HTLV-Ipositive ATLL cell lines and primary ATLL cells is functional, we analyzed the autophosphorylation of c-Met in response to HGF treatment. A signal of Mr 140,000 representing autophosphorylation of c-Met was detected in c-Met-positive KK-1 as described, and primary ATLL cells for the first time, when they were incubated in the presence of HGF (Fig. 2) (16). In those cells, the autophosphorylation of c-Met was not observed in the absence of HGF treatment. In contrast, 
Table I. Expression of c-Met, growth response to HGF, and cytokine assay in primary ATLL cells and ATLL cell lines.

\begin{tabular}{|c|c|c|c|}
\hline & $\begin{array}{c}\text { ATLL cell line } \\
\text { positive/tested cases }\end{array}$ & $\begin{array}{l}\text { Primary ATLL cells } \\
\text { (Chronic type) } \\
\text { positive/tested cases }\end{array}$ & $\begin{array}{l}\text { Primary ATLL cells } \\
\text { (Acute type) } \\
\text { positive/tested cases }\end{array}$ \\
\hline Expression of c-Met & $2 / 8$ & $0 / 7$ & $12 / 14$ \\
\hline Growth response to HGF & $1 / 2$ & $0 / 7$ & 9/11 \\
\hline HGF concentration (plasma) & N.A. & $0 / 6$ & $8 / 8$ \\
\hline HGF concentration (culturea & $2 / 5$ & $2 / 5$ & $6 / 12$ \\
\hline IL-6 concentration (culture $\left.{ }^{a}\right)$ & $2 / 2$ & $4 / 4$ & $5 / 5$ \\
\hline
\end{tabular}

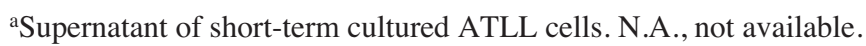

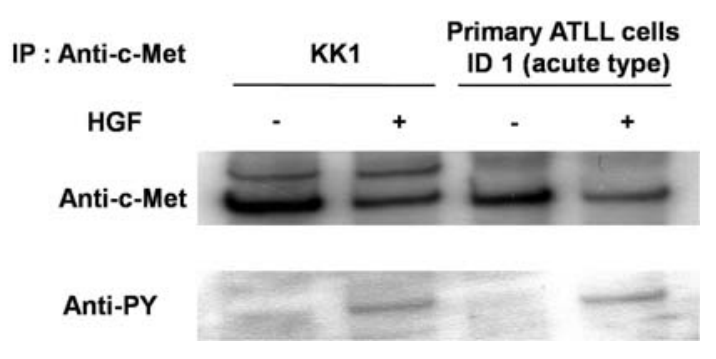

Figure 2. c-Met expressed in an HTLV-1-positive cell line and in primary ATLL cells is autophosphorylated in response to HGF. c-Met-positive KK-1 cells, and primary leukemic cells from a patient with acute ATLL were incubated in the presence (+) or absence (-) of HGF, lysed, immunoprecipitated with anti-c-Met antibody, and blotted with the same antibody or phosphotyrosine (anti-PY) antibody.

no signal representing c-Met or phosphotyrosine could be detected in c-Met-negative ATLL cell lines and primary ATLL cells (data not shown).

HGF induces ATLL cell proliferation. We next measured cell proliferation in primary ATLL cells and ATLL cell lines after stimulation with HGF. As shown in Fig. 3A, KK1, an IL-2-dependent ATLL cell line, showed a proliferative response to HGF in a dose-dependent manner after being deprived of IL-2 in contrast to c-Met negative cell lines. The response was at least partially blocked by anti-HGF or anti-c-Met antibodies (Fig. 3B). Similarly, HGF induced a proliferative response in c-Met-positive ATLL cells from 9 of the 11 acute cases with c-Met expression but not in c-Metnegative ATLL cells from 7 chronic cases (Fig. 3C).

Cytokine assay. The plasma levels of HGF in patients with ATLL are shown in Fig. 4A. The level was most elevated in acute type, and moderate in chronic type ATLL as compared to healthy individuals. Next, we analyzed HGF levels in the supernatants of short-term cultured primary ATLL cells and ATLL cell lines (Fig. 4B). In some of the patients with acute or chronic type ATLL, the cytokine level was relatively elevated as compared to healthy controls. In two (KK1 and ST1) out of 5 IL-2 dependent ATLL cell lines, the level was also relatively high.

To further analyze the mechanism of the increase in plasma HGF levels in patients with acute ATLL, cells not
A

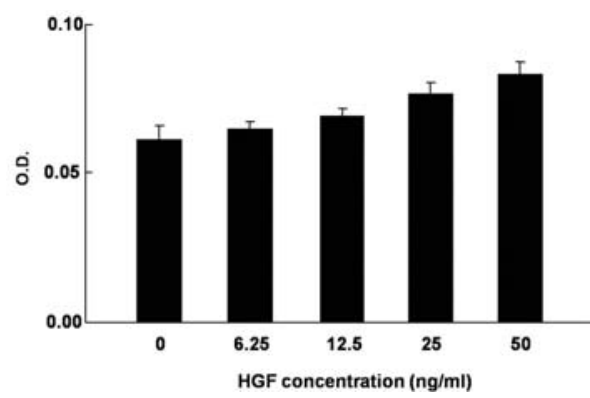

B

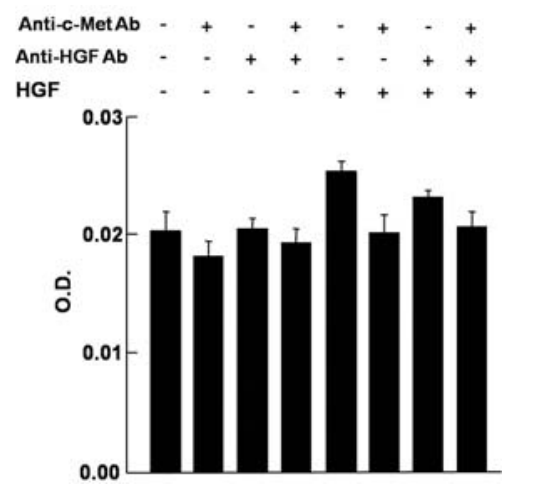

C

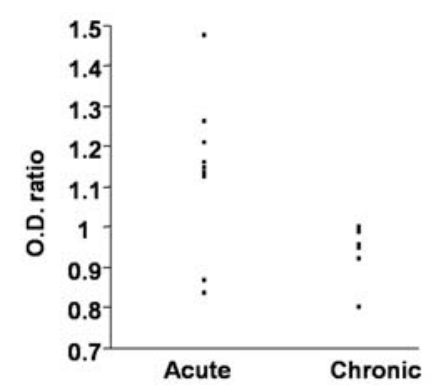

Figure 3. HGF induces proliferation of c-MET-positive cells. (A) The proliferation of c-Met-positive KK1, an IL-2 dependent ATLL cell line, was evaluated in a manner dependent on the dose of HGF after IL-2 deprival by MTS assay. Data are expressed in absorbance unit and are means \pm SD of triplicates. (B) The proliferation of KK1 was evaluated in the absence or presence of HGF $(50 \mathrm{ng} / \mathrm{ml})$, alone or together with anti-HGF or anti-c-Met antibodies by MTS assay. Data are expressed in absorbance unit and are means \pm SD of triplicates. (C) The proliferation of c-Met-positive ATLL cells from acute cases and that of c-Met-negative ATLL cells from chronic cases were evaluated in the presence of HGF $(50 \mathrm{ng} / \mathrm{ml})$ by MTS assay. Data are expressed as ratio of the absorbance unit with that in the absence of HGF of triplicates in each case. The difference between acute and chronic cases were significant ( 1.13 vs. 0.94 , Mann-Whitney $\mathrm{p}=0.016)$. HGF induced a proliferative response (ratio >1.06) in c-Met-positive ATLL cells from 9 of the 11 acute cases but not in the c-Met-negative ATLL cells from 7 chronic cases. 


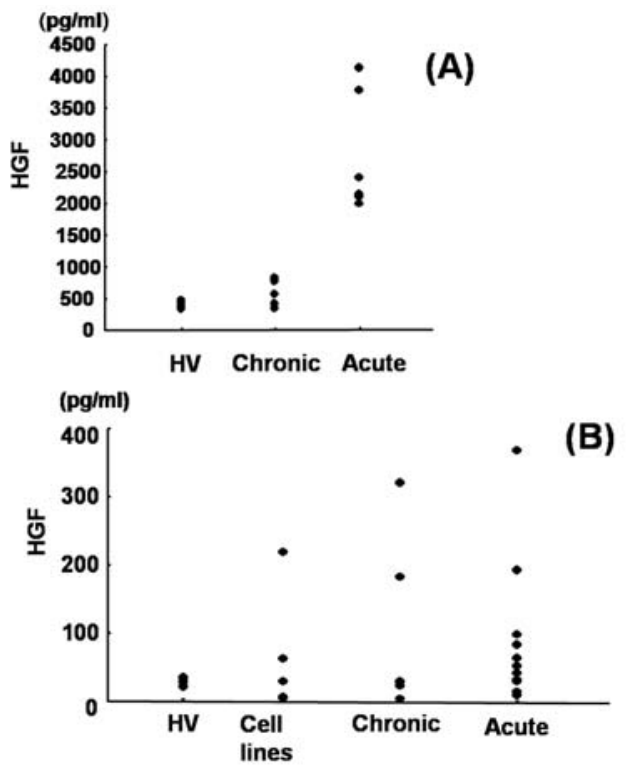

Figure 4. High level of HGF in plasma from ATLL patients and/or supernatant of short-term cultured cells from ATLL patients and HTLV-1positive cell lines. MNCs from patients with ATLL, healthy volunteers (HV), or cell lines were cultured with IL-2. After $72 \mathrm{~h}$ of incubation, supernatant fluid as well as plasma was collected for assays. The concentrations of HGF in the plasma (A) and the supernatant fluid (B) samples were measured by enzyme-linked immunosorbent assay.

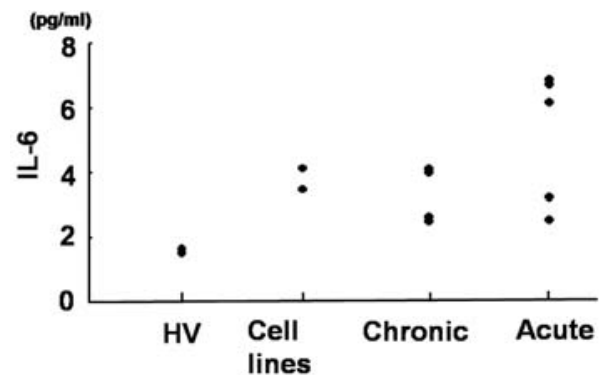

Figure 5. High level of IL-6 in supernatant of short-term cultured cells from ATLL patients and HTLV-1-positive cell lines. MNCs from patients with ATLL, healthy volunteers (HV), or cell lines were cultured with IL-2. After $72 \mathrm{~h}$ of incubation, supernatant fluid was collected for assays. The concentrations of IL-6 in the supernatant fluid samples were measured by enzyme-linked immunosorbent assay.

producing the cytokine in vitro were measured as to the concentration of IL-6, which had been reported to induce HGF production in stromal cells, in supernatant of short-term cultured ATLL cell lines and primary ATLL cells (19). The level was most elevated in acute types including cases with ATLL cells not secreting HGF, and moderate in chronic types and the cell lines as compared to healthy individuals (Fig. 5).

Immunohistochemistry. To evaluate the relationship between tissue-invasiveness and c-Met/HGF expression in ATLL, liver autopsy specimens from 2 patients suffering with liver dysfunction were analyzed. Immunostaining revealed most and some infiltrated atypical lymphocytes were c-Met-positive cells in each one case, respectively (Fig. 6). Hepatocytes
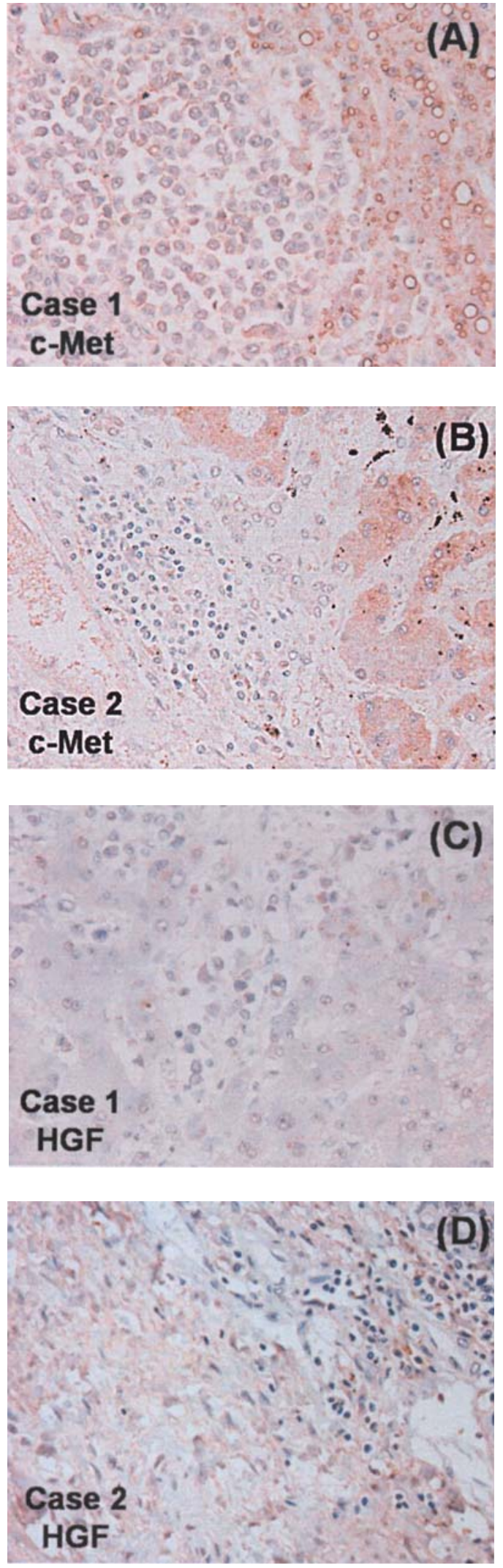

Figure 6. Immunohistochemical staining of c-Met and HGF in invasive ATLL, and adjacent normal hepatocytes and srtomal fibroblasts from patients suffering from liver dysfunction. (A and C) Case 1 showed expression of c-Met in most of infiltrating large atypical lymphocytes and that of HGF in some of the atypical cells. Hepatocytes were positive for c-Met and negative for HGF, respectively. (B and D) Case 2 showed expression of c-Met in some large atypical lymphocytes. Weak expression of HGF was shown in the cytoplasm of stromal fibroblasts but was rare in ATLL cells. 
were stained weak with anti-c-Met antibody as described previously (20). In the case with c-Met expression in most atypical lymphocytes, some of the cells were also positive for HGF. In the other case, HGF was positive in most adjacent stromal fibroblasts but rare in atypical lymphocytes.

\section{Discussion}

$\mathrm{HGF} / \mathrm{c}-$ Met signaling has been shown to play a significant role in promoting tumor cell invasion and metastasis in a wide variety of human tumors $(10,11,13,14)$. We previously found that the expression level of c-Met was higher in leukemic cells of acute type than chronic type ATLL by microarray-based gene expression profiling. Furthermore, the plasma concentration of HGF was increased in most acute and some chronic cases although the expression was not significantly detected in leukemic cells by microarray and PCR (17). We also previously reported that c-Met expression in ATLL was associated with liver-invasiveness of the disease (16). Here, we studied HGF/c-Met interaction using ATLL cell lines, primary leukemic cells and liver autopsy specimens from patients with the disease to elucidate the mechanism of multi-step carcinogenesis and tissue-invasiveness.

We first compared the significance of c-Met and HGF on the clinical features of ATLL. Expression of c-Met but not HGF was increased in acute cases as compared to chronic cases and associated with poor prognosis. In contrast to HGF expression in leukemic cells, plasma HGF concentration was higher in acute cases. Collectively, both c-Met expression in leukemic cells and concentrations of HGF in plasma were increased in most patients with acute ATLL, but rare in patients with chronic ATLL.

Overexpression of HGF and/or c-Met has been reported in various human cancers. Some tumor cell-derived factors, such as IL-1, IL-6 and TNF- $\alpha$, are involved in the overexpression of HGF in stromal fibroblasts $(18,21)$. Thus, such growth factors produced in stromal cells interact with the receptors expressed on tumor cells (paracrine pattern). In addition, malignant tumor cells also frequently produce growth factors and their receptors (autocrine pattern). Therefore, the $\mathrm{HGF} / \mathrm{c}-\mathrm{Met}$ pathway plays an important role during tumor progression in a paracrine pattern and/or autocrine pattern $(22,23)$. The levels of HGF, and/or IL-6 were elevated in the supernatant of short-term cultured ATLL cells from some patients with acute or chronic disease as well as the cell lines KK1 and ST1. Notably, the IL-6 level in the supernatant was elevated in some cases without an elevation of HGF in the supernatant. These results suggest autocrine and/or paracrine growth stimulated by HGF and c-Met in acute ATLL cells secreting HGF and/or IL-6 which induce production of HGF by stroma cells, respectively. Plasma concentrations of IL-6 in the acute cases were significantly higher than those in the chronic cases of ATLL in our previous study (24). ATLL cells as well as HTLV-1 infected cells from HTLV-1 carriers and patients with HTLV-1 associated myelopathy secrete not only IL- 6 but other HGF-inducers such as IL- $1 \beta$ and TNF- $\alpha$, through which the production of HGF in stromal cells could be up-regulated (25-27).

The expression of c-Met in c-Met-positive ATLL cells from an acute case was functional as well as in KK1 by detecting autophosphorylation of the protein after HGF treatment. Furthermore, we showed for the first time that HGF induced the proliferation of primary ATLL cells from most c-Met-positive acute cases examined as well as the KK1 cell line in contrast to c-Met-negative cells. This effect was at least partially blocked by antibodies to HGF and cMet in KK1. These results strongly suggest the c-Met/HGF interaction to be an important event during the acute transformation of ATLL from the chronic phase. Although the HGF concentration was elevated in supernatant of KK1 cells and plasma of the acute case, autophosphorylation of c-Met was not detected in those cells without HGF treatment possibly because the concentration was not high enough to induce autophosphorylation. Interestingly, liver dysfunction associated with ATLL invasion was detected in three of the $12 \mathrm{c}$-Met positive cases in contrast to none of the 9 negative cases in this series. In two of the cases, infiltrated ATLL cells and adjacent stromal cells in liver were shown to be positive for c-Met/HGF and HGF, respectively, suggesting the autocrine and paracrine loop. The invasion by ATLL cells of organs such as the liver could expose the cells to hypoxia and induce c-Met expression as hypothesized in invasive and metastatic cancers $(10,16,28)$. Also, HGF concentration could be elevated at invasive lesion secreted by ATLL cells or adjacent stromal cells $(18,23)$.

Given that the JAK-STAT signaling pathway is activated in the leukemic cells of patients with advanced ATLL (29), it may be relevant that binding sites for STAT1/STAT3 are present in the promoter regions of c-Met. The mechanism of overexpression of c-Met includes amplification of the gene (30). However, we did not detect a significant difference in DNA content at the c-Met locus between chronic and acute ATLL in our previous study (17). It is thus possible that JAKSTAT signaling contributes to the transcriptional activation of c-Met.

IL-2/IL-2R, IL-15/IL-15R and chemokine I-309 loop have been reported to induce autocrine and/or paracrine growth of aggressive ATLL cells (31-33). However, plasma levels of IL-2 and IL-15 were low in those studies. In contrast, HGF level in some acute cases were more than $4 \mathrm{ng} / \mathrm{ml}$, which could induce some proliferation in KK1 and primary ATLL cells. Despite low plasma concentration of HGF, interestingly, the level in supernatant of short-term cultured ATLL cells from some chronic types was also elevated as acute ATLL. Although c-Met was not expressed in chronic types, the secretion of HGF by the cells after IL-2 stimulation might reflect the early phase of the transition to acute ATLL. There have been reports on several targets for the treatment of ATLL (34-37). The c-Met pathway is among drug targets in cancer progression and provides at least three avenues of selective anticancer development: antagonism of ligand/ receptor interaction, inhibition of TK catalytic activity, and blockade of intracellular signaling. Human clinical trials in two of the three areas are now underway $(10,11,22,23)$. Our study revealed that blocking the pathway might be effective against aggressive ATLL as well as solid cancers.

In conclusion, we provide the first evidence of autocrine and/or paracrine growth of primary leukemic cells and tissueinvasive cells stimulated by HGF and c-Met in aggressive ATLL secreting HGF and/or IL-6, respectively. In addition, 
the c-Met/HGF system may represent a suitable target for the treatment of ATLL.

\section{Acknowledgements}

We wish to thank Mr. Masanobu Anami, M.T., C.T., at the Department of Pathology, Nagasaki University Hospital, for his excellent cooperation on immunohistochemical staining.

\section{References}

1. Uchiyama T, Yodoi J, Sagawa K, Takatsuki K and Uchino H: Adult T-cell leukemia: clinical and hematologic features of 16 cases. Blood 50: 481-492, 1977.

2. Poiesz BJ, Ruscetti FW, Gazdar AF, Bunn PA, Minna JD and Gallo RC: Detection and isolation of type $C$ retrovirus particles from fresh and cultured lymphocytes of a patient with cutaneous T-cell lymphoma. Proc Natl Acad Sci USA 77: 7415-7419, 1980.

3. Taylor GP and Matsuoka M: Natural history of adult T-cell leukemia/lymphoma and approaches to therapy. Oncogene 24: 6047-6057, 2005

4. Shimoyama M: Diagnostic criteria and classification of clinical subtypes of adult T-cell leukaemia-lymphoma. A report from the Lymphoma Study Group (1984-1987). Br J Haematol 79: 428-437, 1991

5. Shimoyama M: Chemotherapy of ATL. In: Adult T-Cell Leukemia. Takatsuki K (ed). Oxford University Press, Oxford, pp221-237, 1994

6. Pawson R, Mufti GJ and Pagliuca A: Management of adult T-cell leukaemia/lymphoma. Br J Haematol 100: 453-458, 1998.

7. Tsukasaki K, Utsunomiya A, Fukuda H, et al: VCAP-AMPVECP compared with biweekly CHOP for adult T-cell leukemialymphoma: Japan Clinical Oncology Group Study JCOG9801. J Clin Oncol 25: 5458-5464, 2007.

8. Boros P and Miller CM: Hepatocyte growth factor: a multifunctional cytokine. Lancet 345: 293-295, 1995.

9. Furge KA, Zhang YW and Vande Woude GF: Met receptor tyrosine kinase: enhanced signaling through adapter proteins. Oncogene 19: 5582-5589, 2000.

10. Boccaccio C and Comoglio PM: Invasive growth: a METdriven genetic programme for cancer and stem cells. Nat Rev Cancer 6: 637-645, 2006.

11. Peruzzi B and Bottaro DP: Targeting the c-Met signaling pathway in cancer. Clin Cancer Res 12: 3657-3660, 2006

12. Beilmann M, Vande Woude GF and Dienes HP and Schirmacher P: Hepatocyte growth factor-stimulated invasiveness of monocytes. Blood 95: 3964-3969, 2000.

13. Borset M, Hjorth-Hansen H, Seidel C, Sundan A and Waage A: Hepatocyte growth factor and its receptor c-met in multiple myeloma. Blood 88: 3998-4004, 1996.

14. Capello D, Gaidano G, Gallicchio M, et al: The tyrosine kinase receptor met and its ligand HGF are co-expressed and functionally active in HHV-8 positive primary effusion lymphoma. Leukemia 14: 285-291, 2000

15. Yamada Y, Kamihira S, Murata K, et al: Frequent hepatic involvement in adult $\mathrm{T}$ cell leukemia: comparison with nonHodgkin's lymphoma. Leuk Lymphoma 26: 327-335, 1997.

16. Imaizumi Y, Murota H, Kanda S, et al: Expression of the c-Met proto-oncogene and its possible involvement in liver invasion in adult T-cell leukemia. Clin Cancer Res 9: 181-187, 2003.

17. Choi YL, Tsukasaki K, O'neill MC, et al: A genomic analysis of adult T-cell leukemia. Oncogene 47: 2163-2173, 2006.

18. Masuya D, Huang C, Liu D, et al: The tumour-stromal interaction between intratumoral c-Met and stromal hepatocyte growth factor associated with tumour growth and prognosis in non-small-cell lung cancer patients. Br J Cancer 90: 1555-1562, 2004.
19. Khan KN, Masuzaki H, Fujishita A, et al: Interleukin-6- and tumour necrosis factor alpha-mediated expression of hepatocyte growth factor by stromal cells and its involvement in the growth of endometriosis. Hum Reprod 20: 2715-2723, 2005.

20. Prat M, Narsimhan RP, Crepaldi T, Nicotra MR, Natali PG and Comoglio PM: The receptor encoded by the human c-MET oncogene is expressed in hepatocytes, epithelial cells and solid tumors. Int J Cancer 49: 323-328, 1991.

21. Nakamura T, Matsumoto K, Kiritoshi A, Tano Y and Nakamura T: Induction of hepatocyte growth factor in fibroblasts by tumorderived factors affects invasive growth of tumor cells: in vitro analysis of tumor-stromal interactions. Cancer Res 57: 3305-3313, 1997.

22. Mazzone $\mathrm{M}$ and Comoglio PM: The Met pathway: master switch and drug target in cancer progression. FASEB J 20: 1611-1621, 2006.

23. Matsumoto $\mathrm{K}$ and Nakamura T: Hepatocyte growth factor and the Met system as a mediator of tumor-stromal interactions. Int J Cancer 119: 477-483, 2006.

24. Yamamura M, Yamada Y, Momita S, Kamihira S and Tomonaga M: Circulating interleukin-6 levels are elevated in adult T-cell leukaemia/lymphoma patients and correlate with adverse clinical features and survival. Br J Haematol 100: 129-134, 1998.

25. Yamada Y, Ohmoto Y, Hata T, et al: Features of the cytokines secreted by adult T-cell leukemia (ATL) cells. Leuk Lymphoma 21: 443-447, 1996.

26. Tendler CL, Greenberg SJ, Burton JD, et al: Cytokine induction in HTLV-I associated myelopathy and adult T-cell leukemia: alternate molecular mechanisms underlying retroviral pathogenesis. J Cell Biochem 46: 302-311, 1991.

27. Yamano Y, Machigashira K, Ijichi S, Usuku K, Kawabata M, Arimura K and Osame M: Alteration of cytokine levels by fosfomycin and prednisolone in spontaneous proliferation of cultured lymphocytes from patients with HTLV-I-associated myelopathy (HAM/TSP). J Neurol Sci 151: 163-167, 1997.

28. Gasparini G, Longo R, Fanelli M and Teicher BA: Combination of antiangiogenic therapy with other anticancer therapies: results, challenges, and open questions. J Clin Oncol 23: 1295-1311, 2005 .

29. Migone TS, Lin JX, Cereseto A, et al: Constitutively activated Jak-STAT pathway in T-cells transformed with HTLV-I. Science 269: 79-81, 1995.

30. Danilkovitch-Miagkova A and Zbar B: Dysregulation of Met receptor tyrosine kinase activity in invasive tumors. J Clin Invest 109: 863-867, 2002

31. Kukita $\mathrm{T}$ and Arima N: Autocrine and/or paracrine growth of adult T-cell leukaemia tumour cells by interleukin 15 . Br J Haematol 119: 467-474, 2002.

32. Yamada Y, Tsukasaki K, Kamihira S, et al: Interleukin-15 (IL-15) can replace the IL-2 signal in IL-2-dependent adult T-cell leukemia (ATL) cell lines: expression of IL-15 receptor alpha on ATL cells. Blood 91: 4265-4272, 1998.

33. Ruckes T, Saul D, Van Snick J, Hermine O and Grassmann R: Autocrine antiapoptotic stimulation of cultured adult T-cell leukemia cells by overexpression of the chemokine I-309. Blood 98: 1150-1159, 2001.

34. Waldmann TA, Goldman CK, Bongiovanni KF, et al: Therapy of patients with human T-cell lymphotrophic virus I-induced adult T-cell leukemia with anti-Tac, a monoclonal antibody to the receptor for interleukin-2. Blood 72: 1805-1816, 1988.

35. Mori N, Yamada Y, Ikeda S, et al: Bay 11-7082 inhibits transcription factor NF-kappaB and induces apoptosis of HTLV-Iinfected T-cell lines and primary adult T-cell leukemia cells. Blood 100: 1828-1834, 2002.

36. Zhang Z, Zhang M, Goldman CK, Ravetch JV and Waldmann TA Effective therapy for a murine model of adult T-cell leukemia with the humanized anti-CD52 monoclonal antibody, Campath1H. Cancer Res 63: 6453-6457, 2003.

37. Mori N, Matsuda T, Tadano M, et al: Apoptosis induced by the histone deacetylase inhibitor FR901228 in human T-cell leukemia virus type 1-infected T-cell lines and primary adult T-cell leukemia cells. J Virol 78: 4582-4590, 2004. 